\title{
Compulsivity and Free Will
}

\author{
Damiaan Denys* \\ Department of Psychiatry, Academic Medical Center (AMC), University of Amsterdam; and the Netherlands Institute for Neuroscience, an Institute of the \\ Royal Netherlands Academy of Arts and Sciences, Amsterdam, The Netherlands
}

Received 23 January 2013; Accepted 1 May 2013; First published online 28 June 2013

Key words: Compulsivity, free will, impulsivity.

"The perfection of a science is shown in the perfection of its language," Condillac said in $1746 .{ }^{1}$ A concept that is gaining in popularity and cropping up in scientific articles with increasing regularity is "compulsivity." Off the cuff, the word "compulsive" makes us think of something that is controlled, repeated, inexorable, repetitive, imperative, stereotyped, and necessary-something you "have to" do. Compulsivity is associated with addiction, obsessive-compulsive disorder, paraphilia, obesity, anorexia, bulimia, hoarding, pathological buying and gambling, kleptomania, body dysmorphic disorder, trichotillomania, etc. But what is compulsivity? Nobody knows exactly. Though the word is often used, no one has ever come up with a clear definition. And yet "compulsivity" is more than just another new word. Funds have been made available to research it, researchers have applied for this funding, patients have been interviewed, control subjects have been approached, PhD projects have been launched, scales have been designed, papers have been written and rejected, symposia have been set up, lectures have been cancelled, tests have been designed, people have been placed under scanners, and extensive research has been carried out on animals. People have deliberated, assessed, and drawn conclusions, and money has been allocated and withdrawn about a word that has not even been defined. Condillac's opinion about psychiatry would be firm.

What is compulsivity? Can we learn something from the different scientific contexts in which compulsivity occurs? With addiction, compulsivity is understood as the final stage of a process of positive reinforcement that results in a habit from which the individual can no longer escape: Once caught in the compulsive trap, there is no natural way to go back. With compulsive disorder, the emphasis lies on the subjective experience of loss of control. The word subjective is important here because there is no true

*Address for correspondence: Prof. Dr. Damiaan Denys, AMC-Department of Psychiatry, PA.2-179, PO Box: 75867, 1070 AW Amsterdam, Netherlands.

(Email: ddenys@gmail.com) loss of control, just a feeling of loss of control. Being compelled to think or do something is explicitly experienced as pathological. It is an interesting paradox that patients with compulsive disorder bring about precisely what they are seeking to preventperforming compulsions for fear of loss of control, which themselves result in a loss of control. With tics, compulsivity is closer to the idea of a motoric, prereflective component that precedes explicit awareness. Tics are a peculiar hybrid of a voluntary and an involuntary act. With trichotillomania, the emphasis is on the urge-the uncontrollable, impulsive aspect. Performing the act may indeed be compulsive, but it is also satisfying. This disorder confronts us with the difficult distinction between impulsivity and compulsivity. In obsessive-compulsive personality disorder, compulsivity seems to be associated with a personalitylinked, imperative engagement with the world, a form of rigidity with no functional meaning and usually with a total lack of insight on the part of the patient. In normal bedtime rituals of children, compulsivity manifests itself in the compelling force of ceremonial rituals that clearly function as an ordering principle for their awakening world. The fact that compulsivity does not exclusively belong to the field of pathology is clearly demonstrated by the countless, sometimes bizarre, rituals performed by athletes. Again, these have a functional significance that is linked to performance. And last, compulsivity is not an exclusively human trait but manifests itself in different ways among different species of animals, with the repetitive element being the most salient.

There is no denying that compulsivity in psychiatry currently has several meanings, though the common use of a single term constantly creates a certain illusion of unambiguity. There are two obvious questions to ask. Firstly, are there different "compulsivities" that we incorrectly label with a single term? Should we in fact be referring to compulsivity type 1 , type 2 , type 3 , etc? Or is there a single type of compulsivity that manifests itself in different variants? With the first question, we must then ask ourselves what the distinguishing features are of the different types, and in the second, 
we should ask what makes up the true core of compulsivity that links all the variants.

What is the essence of compulsivity (if there is one), or what do the different variants have in common (if there are several)? If we use Ockham's razor to pare away everything that is not necessary for maintaining compulsivity, the following elements appear superfluous, as they are not present in all forms of compulsivity: the process-related final stage that is characteristic of addiction, the preceding anxiety with compulsive disorder, the functional nature of the rituals for the sake of control, the repetitive element with tics, stereotypy among animals, the characteristic urge with trichotillomania, and the relief and satisfaction while performing tics. These features are not indispensable for an understanding of compulsivity. Present in all variants, however, and we can therefore call it a precondition, is the fact that a particular behavior "has to" be carried out. The patient, individual, child, or animal "has to" perform that particular act. Compulsivity is the urge to carry out an act, or, conversely, it is the impossibility of stopping or not carrying out a specific act or thought. Something "has to" be thought or done. Compulsivity is therefore the lack of control over one's own behavior.

In compulsivity, the aspect of "having to" is of a different kind than in acts required by an external agent. If I have to polish my shoes because my wife has instructed me to do so for her parents' wedding anniversary, that is a different kind of "having to" than having to polish my shoes because I think that my parents will die if I do not. "Having to" is clearly of two distinct types. An externally imposed act feels different to one that is internally imposed. We only use the term "compulsive" if an internal agent is present and the compulsion comes from the individuals themselves. Compulsivity is the inability to not perform an act, with a subjective feeling of loss of control vis-à-vis oneself.

In conclusion, we can say that compulsivity is the result of an internal struggle, akin to disappointment or frustration in which the "self" always loses. In this respect, it is entirely understandable that it is especially compulsivity that generates a feeling of loss of control. This explains why a patient's suffering is always associated with compulsivity, with "having to" vis-à-vis themselves. The experience of compulsivity in turn generates shame, guilt, lack of self-confidence, and anxiety. Compulsivity is a harsh confrontation with the fact that we as human beings are determined by something other than ourselves, that we have brains that think and act independently, that we live in an environment that follows its own rules. Perhaps we find it more difficult to surrender to ourselves than to engage with other people and with the world. The fact that we can experience something exceptional like compulsivity and that this experience then contrasts sharply with others illustrates that we most certainly have free will. Indeed, a feeling of compulsion or compulsivity can only be experienced against a background of free will, just as a lie is only possible against a background of truth.

\section{Reference}

1. de Condillac EB. Essai sur l'origine des connaissances humaines [Essay on the origin of human knowledge]. Amsterdam, Netherlands: Pierre Mortier; 1746. 